\title{
Hydrologic assessment of blind inlet performance in a drained closed depression
}

\author{
M. Williams, S.J. Livingston, C.J. Penn, and J.M. Gonzalez
}

\begin{abstract}
Surface inlets installed in agricultural closed depressions can transport sedimentand nutrient-laden runoff directly to receiving streams or water bodies. Replacing tile risers with blind inlets has the potential to decrease these sediment and nutrient loads, but adoption of blind inlets has been met with hesitation from producers who fear that changes to the surface inlet may result in additional water ponding, crop damage, or crop loss. The objectives of this study were to assess hydrologic performance of blind inlets over time, and to determine whether blind inlets influenced the hydrology of a closed depression compared to a tile riser. Hydrograph characteristics including flow duration, time to peak flow, peak flow rate, and cumulative flow were evaluated for 549 storm events over a 12-year period (2006 to 2017) for a pair of closed depressions in northeastern Indiana. Surface water could be drained in both depressional areas with either a tile riser or blind inlet. Results showed that blind inlet infiltration rates declined approximately linearly over time $\left(1.4 \mathrm{~cm} \mathrm{~h}^{-1} \mathrm{y}^{-1}\right)$. While changes in infiltration were largely controlled by annual tillage practices at the study sites, findings suggest that blind inlets have an effective service life of 8 to 10 years under the study conditions. Surface water management practices significantly influenced depression hydrology; however, the practices functioned differently between fields. Blind inlets did not influence the frequency of discharge, but they may increase or decrease the duration of flow and cumulative flow compared to a tile riser depending on the extent of subsurface tile drainage within the closed depression. Findings from this study underscore the inherent connections between surface and subsurface hydrologic processes in drained closed depressions and how these connections may influence both water quantity and water quality.
\end{abstract}

Key words: infiltration — pothole—surface inlet—surface runoff—tile drainage — tile riser

Glaciation throughout much of the midwestern United States resulted in a complex landscape of moraines, till plains, meltwater channels, and outwash plains (Dreimanis 1977). Closed drainage basins or potholes are common geomorphological landforms found across the region where hillslopes encircle low spots on the landscape that vary in size (square meters to hectares) and depth (centimeters to meters) (Norton 1986). Prior to European settlement, these closed depressions would have served as temporarily flooded to permanently flooded wetlands, with van der Valk and Pederson (2003) estimating that 12.6 million depressional wetlands may have once covered the $700,000 \mathrm{~km}^{2}$ prairie pothole region extending from central Iowa to the Canadian provinces of Manitoba, Saskatchewan, and Alberta. Over the past 150 years, artificial drainage systems
Erie Basin may exceed 75,000 (Feyereisen et al. 2015). In the Minnesota River basin, more than 250,000 (1 to $11 \mathrm{~km}^{-2}$ ) closed depressions are farmed and likely drained (Mueller and Wehrenberg 1994).

Surface runoff draining through the surface inlet to the subsurface tile network has the potential to transport sediment, nutrients, and other contaminants directly from fields to receiving waters. In agricultural watersheds, direct correlations between watershed nutrient fluxes and the extent of closed depressions within the watershed have been observed, with elevated nutrient loss reported for watersheds with a greater proportion of land area as closed depressions (Smith et al. 2008). Tomer et al. (2010) also concluded that surface inlets in tile-drained landscapes "are an underappreciated source of P [phosphorus]." Using hydrograph separation techniques, the authors found that surface inlets delivered at least $75 \%$ of the phosphorus (P) load discharged from tile drain networks in the Tipton Creek watershed (Iowa). Modifications to surface inlet design and implementation of management practices that decrease surface flow rates have therefore been proposed to decrease sediment and nutrient loads from drained closed depressions. Planting grass buffer strips around surface inlets (Oolman and Wilson 2003; Miller et al. 2012), encircling surface inlets with woodchip-filled filter socks (Shipitalo and Tomer 2015), using alternative surface inlet designs (Oolman and Wilson 2003; Li et al. 2017), and installing gravel inlets (Feyereisen et al. 2015) or blind inlets (Smith and Livingston 2013) have been evaluated, with authors reporting varying degrees of sediment and nutrient load reductions.

Altering or replacing surface inlets in farmed closed depressions has been met with hesitation from producers who fear that changes to the surface inlet may result in additional water ponding, crop damage, or crop loss. Replacing a traditional tile riser with a blind inlet represents perhaps the largest modification to surface inlet design,

Mark Williams is a research agricultural engineer, Stanley J. Livingston is a soil scientist, Chad J. Penn is a research soil scientist, and Javier $\boldsymbol{M}$. Gonzalez is a research soil scientist, all with the USDA Agricultural Research Service (ARS) National Soil Erosion Research Laboratory, West Lafayette, Indiana. 
whereby the tile riser is removed and a gravel box overlain with coarse soil is installed and used to remove ponded water from the depression (Smith and Livingston 2013). Previous studies have documented significant sediment and nutrient load reductions with blind inlets compared to other surface inlet designs (Wilson et al. 1999; Smith and Livingston 2013; Smith et al. 2015; Feyereisen et al. 2015), and, as a result, they are being promoted as part of Conservation Practice Standard 620 for their potential to filter surface runoff (USDA NRCS 2010). To date, however, there have been no studies that have examined if and how installation of a blind inlet alters the hydrology of a closed depression, which is often the largest barrier to practice implementation.

The objectives of this study were to determine whether blind inlets influenced the hydrology of a closed depression compared to a tile riser, and to assess hydrologic performance of blind inlets over time. Hydrograph characteristics including flow duration, time to peak flow, peak flow rate, and cumulative flow were evaluated for storm events over a 12-year period (2006 to 2017) for a pair of closed depressions in northeastern Indiana where surface water could be drained in both depressional areas with either a tile riser or blind inlet. Sediment, nutrient, and pesticide load reductions achieved through installation of blind inlets in these depressions have been previously reported (Smith and Livingston 2013; Smith et al. 2015; Feyereisen et al. 2015; Gonzalez et al. 2016). Detailed hydrologic analysis of these long-term study sites not only provides greater insight into blind inlet performance and service life, but also provides greater understanding of the processes controlling contaminant removal and offers recommendations for future blind inlet design and implementation.

\section{Materials and Methods}

Site Description. A pair of fields (ADE and ADW) containing closed depressions located in the St. Joseph River basin in northeastern Indiana (48²8'20.19” N, 8459'28.50” W) were monitored as part of the current study (figure 1). Both fields have been monitored since 2005 as part of the Conservation Effects Assessment Project (CEAP; Mausbach and Dedrick 2004). Drainage areas for ADE and ADW are 4.88 and 4.01 ha, respectively. The fields are separated by a $3 \mathrm{~m}$ wide berm that serves as a road to the monitoring station and prevents surface runoff from crossing from one depression to the other. Both fields are tile drained, with laterals positioned approximately $0.9 \mathrm{~m}$ below the soil surface (figure 1). Subsurface drainage intensities in ADE and ADW are 0.009 and $0.005 \mathrm{~m}^{-1}$, respectively. For context, Schilling et al. (2015) reported drainage intensities ranging from 0.005 to $0.04 \mathrm{~m}^{-1}$ (i.e., drainage of wet spots to systematic pattern drainage) for fields in the midwestern United States. Dominant soil series in both fields include Glynwood loam (fine, illitic, mesic Aquic Hapludalfs), Morley silty clay loam (fine, illitic, mesic Oxyaquic Hapludalfs), Pewamo silty clay (fine, mixed, active, mesic Typic Argiaquolls), and Wallkill silt loam (fine-loamy, mixed, superactive, nonacid, mesic Fluvaquentic Humaquepts). Both fields were managed by the same producer during the study period. From 2008 to 2017 both fields were managed in a corn (Zea mays L.)-soybean (Glycine max [L.] Merr.)-wheat (Triticum aestivum L.)-oat (Avena sativa L.) rotation. In 2006 and 2007, ADE was planted in corn-soybean, while

\section{Figure 1}

Map of ADE and ADW field sites located in northeastern Indiana. A $3 \mathrm{~m}$ wide berm separates the two fields and prevents surface runoff from crossing from one depression to the other. Location of subsurface tile drain network estimated based on conversations with the landowner and aerial photos.

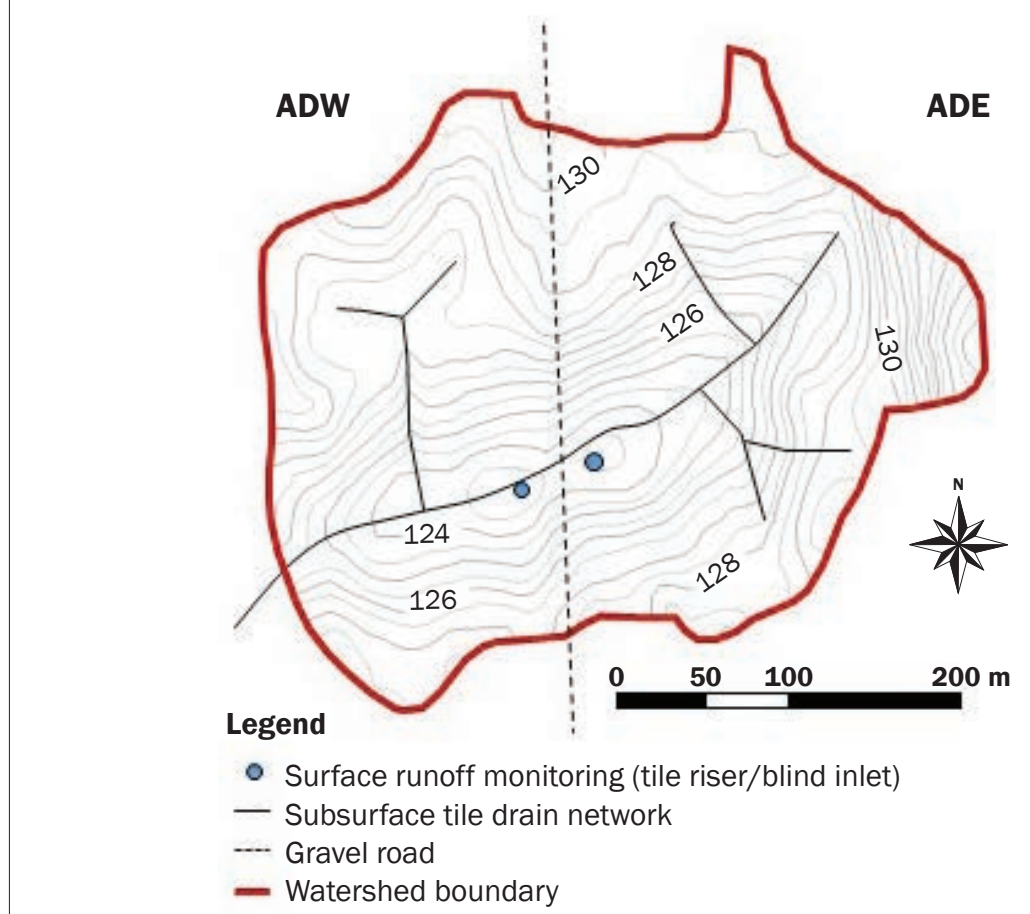

ADW was split into two fields with cornsoybean planted on the northern one-third of the field and alfalfa (Medicago sativa L.) planted on the remainder of the field. Corn, soybean, wheat, and oat were planted after tillage, and approximately $20 \mathrm{~kg} \mathrm{P} \mathrm{ha}^{-1}$ was applied to each crop.

Surface Inlet Installation and Monitoring. The existing tile riser that served to drain surface water in each depression was removed in 2005 and was replaced with two surface water drainage management technologies in each field. Both depressions were fitted with a new tile riser (Precision Intake PI06-01, AgriDrain Co., Adair, Iowa) and a blind inlet. Gate valves determined whether the tile riser or blind inlet was operating. Tile risers consisted of $15 \mathrm{~cm}$ diameter perforated HDPE pipe (40 holes, $2.54 \mathrm{~cm}$ diameter) that extended 0.9 $\mathrm{m}$ above the soil surface. The blind inlets were constructed by excavating a $4.25 \times$ $4.25 \mathrm{~m}$ area to a depth of $1 \mathrm{~m}$. Coarse limestone gravel was backfilled (10-cm-deep layer) and septic tile was placed in a $3 \times$ 
$3 \mathrm{~m}$ pattern on the gravel. An additional $60 \mathrm{~cm}$ of limestone gravel was backfilled on top of the septic tile, geotextile fabric (Typar 3301, Fiberweb, Old Hickory, Tennessee) was placed over the gravel to decrease sedimentation, and the remainder of the hole was backfilled with $30 \mathrm{~cm}$ of coarse soil. The coarse soil (including gravel) was comprised of $20.2 \%, 17.0 \%$, and $62.8 \%$ of $\geq 4$ $\mathrm{mm}, \geq 2$ and $<4 \mathrm{~mm}$, and $<2 \mathrm{~mm}$ particle sizes, respectively. Excluding gravel, the coarse soil was primarily comprised of sand (56.7\%) followed by clay (23.6\%) and silt (19.7\%). For additional details and drawings of the blind inlet installation, see Smith and Livingston (2013).

In each depression, immediately downstream from the gate valves that controlled whether the tile riser or blind inlet was in operation, surface drainage flow was plumbed into a common outlet pipe. Discharge was measured in the common outlet pipe using an area-velocity sensor (Model 2150, Teledyne Isco, Inc., Lincoln, Nebraska). From 2006 through 2009, discharge measurements were made proportional to flow (1 to 10-minute interval) and were subsequently aggregated into 10-minute data. Beginning in 2010, a 10-minute measurement interval was used for discharge. Precipitation was measured at 10-minute intervals using a Vaisala Weather Transmitter (Model WXT510, Vaisala Co., Helsinki, Finland).

Infiltration Rate. Double ring infiltrometers $(90 \mathrm{~cm}$ diameter outer ring; $50 \mathrm{~cm}$ diameter inner ring) were used to measure blind inlet infiltration rate. In 2012, infiltration rates were measured at the blind inlets located in ADE, ADW, and four others located in the same watershed, and constructed using the same design and backfill materials. Rings were pounded into the ground, and the soil was prewetted 1 to 1.5 days prior to measuring infiltration rate. Infiltration rates were measured twice at each location separated by 1 to 3 days. In 2012, blind inlets at ADE and ADW had been installed for 7 years, while the other four blind inlets had only been installed for 1.5 years. Infiltration rate measurements were repeated in 2018 at ADE and ADW (12.8 years after installation) using the same procedure.

Data Analysis. Over the study period (2006 to 2017), 549 precipitation events were observed at the study sites. Rainfall events were defined as $6 \mathrm{~mm}$ of precipitation within a 6 hour period separated by $>6$ hours from additional rainfall. Snowmelt events were identified when discharge increased during winter months (January to March) with no corresponding precipitation. If discharge increased in response to a precipitation event, then hydrograph characteristics including time to peak, peak flow rate, average flow rate, flow duration, and cumulative flow were determined. Time to peak for rainfall events was defined as the time between the start of rainfall and the hydrograph peak. For snowmelt events, time to peak was calculated as the time between the start of flow and the hydrograph peak. Flow duration was defined as the time between the start of flow and when either flow ceased or another event began.

The experimental design for the current study differed from a typical paired field experiment. A before-after control-impact (BACI) experimental design is often characterized by two fields being managed similarly for a specified period of time, and then a treatment would be implemented on one of the fields while the other field would remain as the control (Williams et al. 2015; King et al. 2016). In the current study, surface water was drained from both depressions using either a tile riser or blind inlet by alternating practices between depressions (figure 2). Both depressions, however, were concurrently managed as blind inlets at several times over the study period (i.e., portions of 2006 , 2007, 2008, and 2014, as well as 2015 through 2017; figure 2). To statistically evaluate the effect of surface drainage water management practice on depression hydrology, the data set was considered as two separate BACI experiments: (1) implementation of the tile riser at ADE and the blind inlet at ADW compared to when both ADE and ADW were blind inlets, and (2) implementation of the tile riser at ADW and the blind inlet at ADE compared to when both ADE and ADW were blind inlets. Hydrograph characteristics for each experiment were analyzed using analysis of covariance (ANCOVA) as outlined by Clausen and Spooner (1993) to determine if implementation of the tile riser significantly altered the depression hydrology compared to the blind inlet. Slopes and intercepts of the linear relationships between the control periods and treatment periods were compared. Significantly different slopes (or intercepts when slopes were not significantly different) indicated a treatment effect. Data were analyzed using the "cars" package of R statistical software (R Development Core Team
2011), with a significance level of 0.05 used to determine statistical differences.

\section{Results and Discussion}

Timing and Frequency of Precipitation and Discharge. From 2006 through 2017, 511 rainfall events $>6 \mathrm{~mm}$ occurred at the study fields. An additional 38 snowmelt events (i.e., increase in discharge with no corresponding precipitation) were identified during the study between the months of January and March. Event rainfall over the study period ranged from 6.0 to $134.1 \mathrm{~mm}$ and averaged $18.3 \pm 15.9 \mathrm{~mm}$. Average rainfall depth during events was consistent across seasons, with $17.1 \pm 14.8,18.4 \pm 15.8,20.3 \pm 19.2$, and $16.9 \pm 12.3 \mathrm{~mm}$ of rainfall observed per event in the winter (January to March), spring (April to June), summer (July to September), and fall (October to December), respectively. The frequency of events (rainfall + snowmelt) was also similar throughout the year $\left(3.9 \pm 1.0\right.$ events $\left.\mathrm{mo}^{-1}\right)$. While rainfall depth per event and frequency of events were consistent across the year, seasonal differences in rainfall intensity and duration were observed. Rainfall events during the winter tended to have a lower intensity and longer duration (2.2 $\mathrm{mm} \mathrm{h}^{-1} ; 9.7 \mathrm{~h}$ ) compared to rainfall events in the summer $\left(5.9 \mathrm{~mm} \mathrm{~h}^{-1} ; 4.5 \mathrm{~h}\right)$.

Frequency of discharge (i.e., number of rainfall events with observed flow/total number of rainfall events) did not significantly vary between periods when the fields were managed with the tile riser and periods when the fields were managed with the blind inlet; thus, frequency of discharge data from both periods were pooled together for each field (figure 3). Frequency of discharge at ADW was significantly greater than the frequency of discharge at ADE $(p=0.029)$. Of the 549 rainfall events, discharge was observed during $151(27.5 \%)$ and 196 (35.7\%) rainfall events at $\mathrm{ADE}$ and $\mathrm{ADW}$, respectively. Differences in the frequency of discharge between the two fields primarily occurred during the winter and late fall (figure 3). Discharge from ADW occurred during $67 \%$ to $71 \%$ of rainfall events during the winter, while discharge from ADE occurred during 46\% to $55 \%$ of winter rainfall events. In contrast, discharge only occurred during $6 \%$ to $22 \%$ of rainfall events during the summer for both fields (figure 3). Evapotranspiration is greatest during the summer across the eastern Corn Belt when air temperatures are warm and crops are actively growing, which results 


\section{Figure 2}

Rainfall and discharge (10-minute interval) from (b) ADE and (c) ADW sites between 2006 and 2017. Shaded areas indicate periods of time when the tile riser was operating in the field (nonshaded areas show when the blind inlet was operating).

(a)

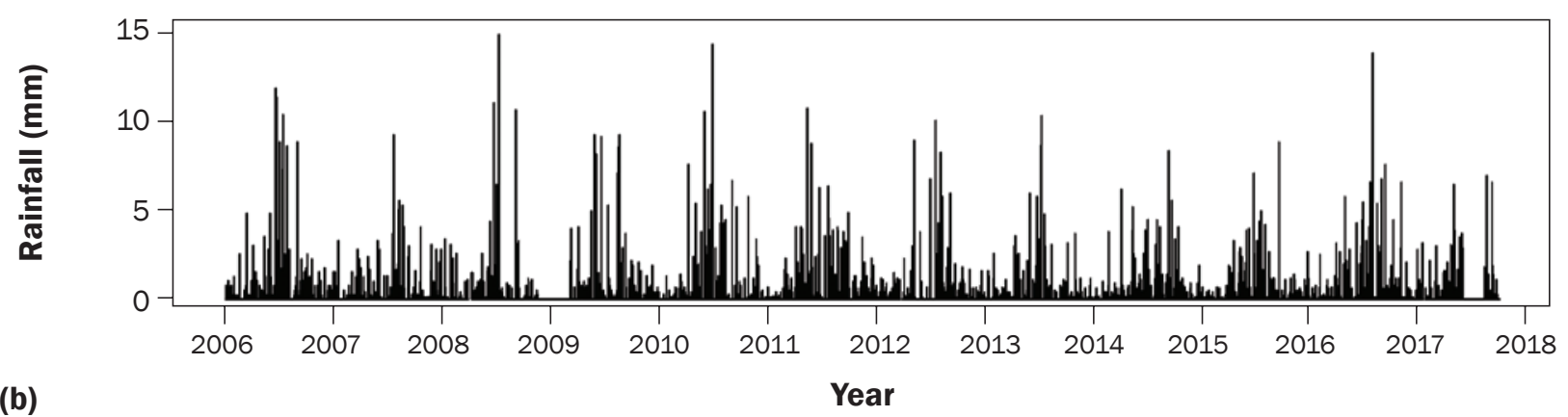

(b)

Year

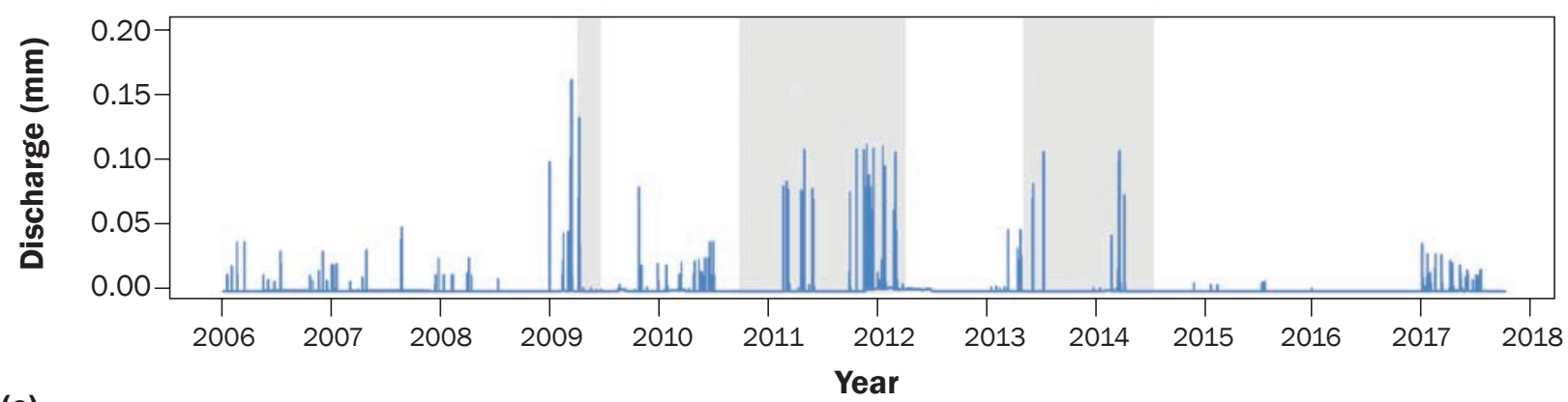

(c)

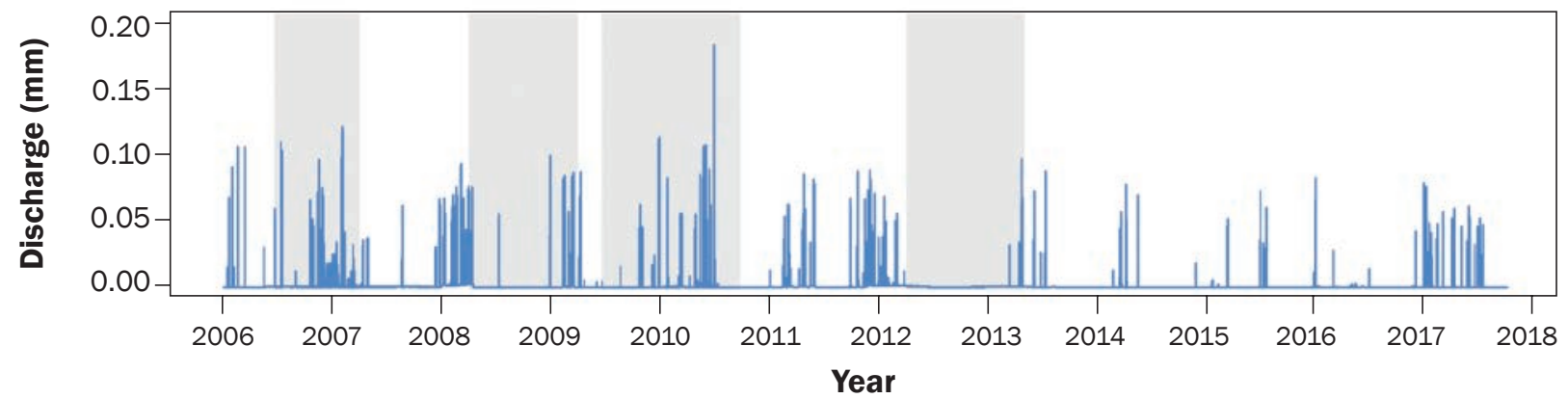

in drier antecedent conditions (King et al. 2014). Larger soil moisture deficits during the summer likely resulted in less frequent flow generation compared to the winter when soils are often at or near field capacity (Lam et al. 2016). Differences in frequency of flow generation observed between ADW and ADE may have been due to differences in soil moisture status between the two fields. Skaggs et al. (1994) reviewed the hydrologic impacts of agricultural drainage and concluded that increasing subsurface drainage intensity increases tile drain discharge, but decreases surface discharge. It is therefore hypothesized that lower subsurface drainage intensity in ADW $\left(0.005 \mathrm{~m}^{-1}\right)$ resulted in wetter antecedent conditions and greater probability of discharge, especially during the winter, compared to $\operatorname{ADE}\left(0.009 \mathrm{~m}^{-1}\right)$.

Depth of surface ponding in ADE and ADW during periods when the fields were managed with the tile riser was calculated based on established relationships between ponding depth and tile riser flow capacity (AgriDrain Co., personal communication, 2018). Surface ponding depth ranged from 2.2 to $28.5 \mathrm{~cm}$ and 2.6 to $33.7 \mathrm{~cm}$ at ADE and ADW, respectively. Average ponding depth was slightly greater at ADE (14.8 \pm $8.1 \mathrm{~cm})$ compared to ADW $(10.5 \pm 7.1 \mathrm{~cm})$, but values were not statistically compared since the fields were never managed with the tile riser concurrently (figure 2). Differences in ponding depth between fields could arise due to several factors including event characteristics and antecedent conditions between periods or fields, as well as depression topography (figure 1). Surface ponding depth did not vary seasonally at either field. Using field contours and average ponding depth, surface ponding would impact 0.11 and 0.16 ha of the field in ADE and ADW, respectively. Calculated areas are consistent with areas of crop damage/loss observed from aerial photos between 2005 and 2017.

Blind Inlet Infiltration Rate. Infiltration rates measured from blind inlets at $\mathrm{ADE}$ and ADW decreased from 12.7 and $11.8 \mathrm{~cm} \mathrm{~h}^{-1}$, respectively, in 2012, to 4.8 and $3.7 \mathrm{~cm} \mathrm{~h}^{-1}$ in 2018 (figure 4). Comparing infiltration rates from blind inlets at ADE and ADW to 
infiltration rates from four newly installed blind inlets that were constructed using the same design and materials revealed that ADE and ADW blind inlet infiltration rate likely declined linearly over the study period. The slope of the regression line between blind inlet infiltration rate in 2012 and 2018 suggests that infiltration rate decreased annually by $\sim 1.4 \mathrm{~cm} \mathrm{~h}^{-1}$ (figure 4). Decreasing blind inlet infiltration rate over time was expected given that the blind inlets are designed to filter eroded hillslope sediments from surface runoff before it enters the subsurface drainage network. Assuming that more sediment accumulated on the surface of the blind inlet (and decreased infiltration rate) when the depression was managed with the blind inlet compared to the tile riser, blind inlet infiltration rate may have decreased more rapidly over time if the two practices had not been alternated over the study period (figure 2). Tile risers were used to drain ponded surface water for $25 \%$ and $33 \%$ of the study period in $\mathrm{ADE}$ and $\mathrm{ADW}$, respectively.

It is important to acknowledge that changes in blind inlet infiltration rate over time at ADE and ADW were largely influenced by field management practices. Both fields were typically double-disked each spring and chisel plowed in the fall throughout the study. It is widely known that tillage greatly increases the risk of erosion and sediment loss from fields compared to no-tillage (Laflen et al. 1978). Oolman and Wilson (2003) indicated that the most effective sediment control practice in closed depressions with surface inlets was to shift from conventional tillage to no-tillage practices. Based on the data collected from ADE and ADW, blind inlets installed in closed depressions with extensive tillage may become ineffective at draining ponded surface water due to impeded infiltration after 8 to 10 years of service. It is conceivable that blind inlets would maintain higher infiltration rates for longer periods of time in fields with reduced or no-tillage extending the service life well beyond 10 years.

Effect of Surface Water Management Practice on Depression Hydrology. The effect of the surface water management practice on depression hydrology was evaluated for both ADE and ADW using a modified BACI study design. Since both fields were managed concurrently as blind inlets during several periods of the study (figure 2), the tile riser was considered as the treatment and the

\section{Figure 3}

Monthly frequency of discharge (i.e., number of events with observed flow/total number of events) for ADE and ADW sites. Frequency of discharge did not significantly vary between periods when the fields were managed with the tile riser and periods when the fields were managed with the blind inlet.

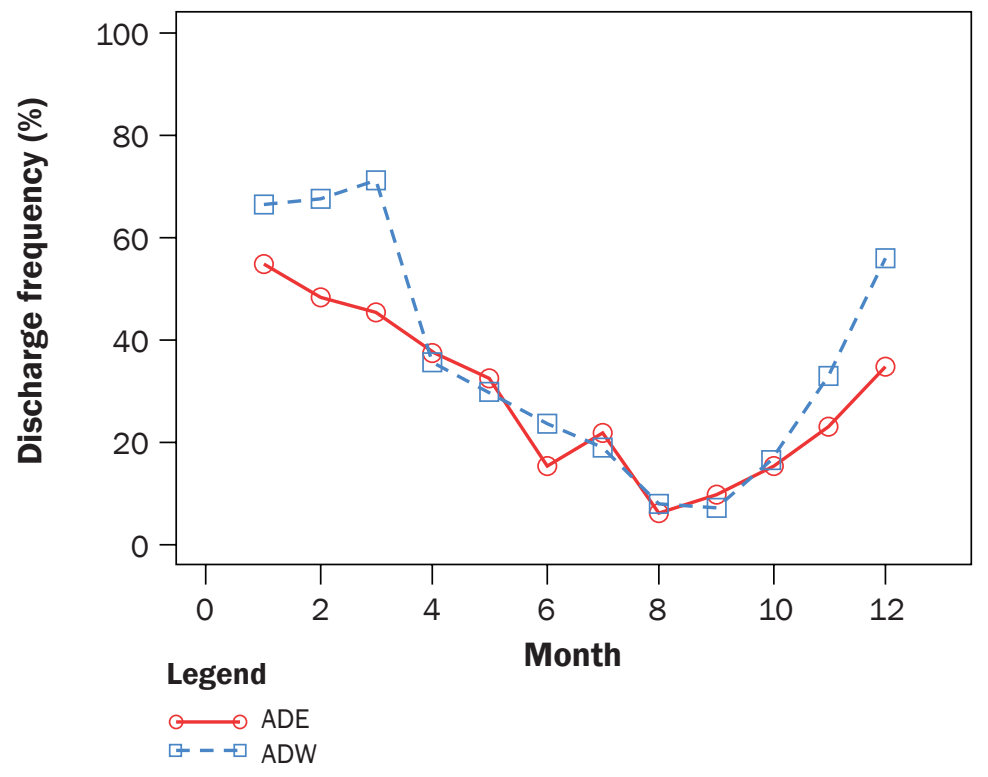

\section{Figure 4}

Blind inlet infiltration rate. Infiltration rate at ADE and ADW sites was measured in 2012 (7 years after blind inlet installation) and 2018 (12.8 years after blind inlet installation). In 2012, infiltration rates were also measured from four recently installed blind inlets (1.5 years after installation; constructed using same design and materials as ADE and ADW). Numbers in parentheses show maximum flow rate through the blind inlet given a surface area of $18 \mathrm{~m}^{2}$.

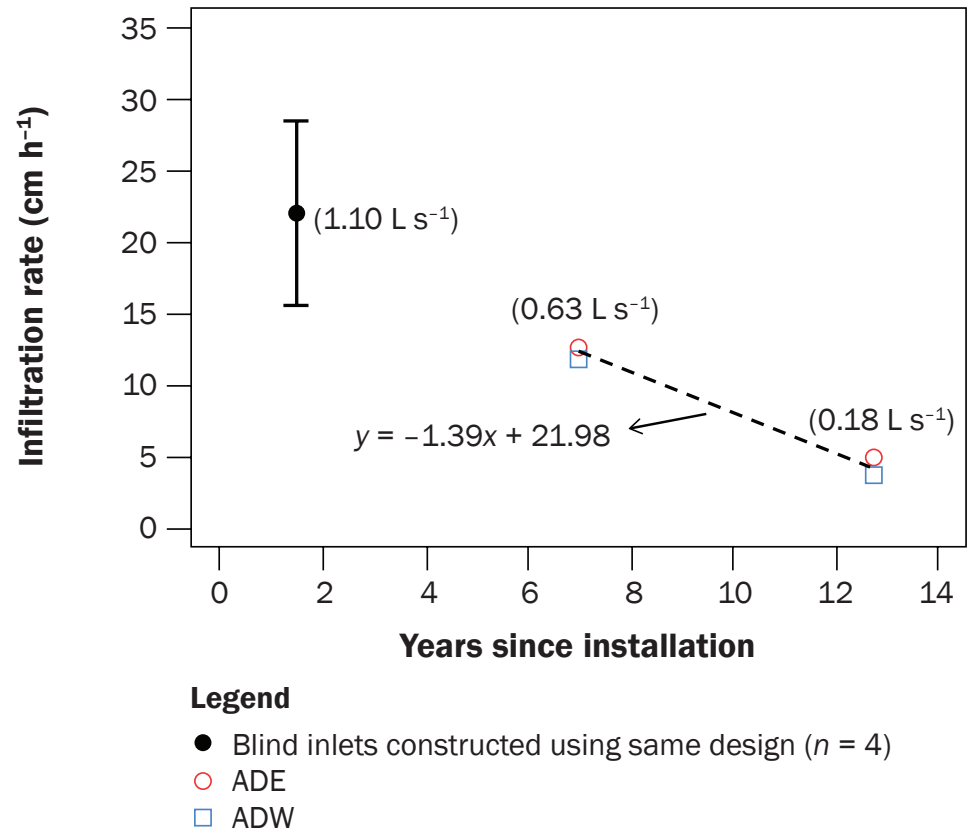


blind inlet as the control. Linear relationships between ADE and ADW were developed for periods of the study (1) when both depressions were managed with blind inlets, (2) when ADE was managed with the blind inlet and ADW was managed with the tile riser, and (3) when ADE was managed with the tile riser and ADW was managed with the blind inlet. Relationships between ADE and ADW are shown graphically in figure 5, with ANCOVA results presented in table 1.

Surface water management practices significantly influenced depression hydrology at both ADE and ADW. The effect of surface water management practices on depression hydrology, however, varied between fields, suggesting that the practices were functioning differently (figure 5; table 1). When the depression in ADE was managed with the tile riser, time to peak and flow duration both significantly decreased, while peak flow rate, average flow rate, and cumulative flow all significantly increased. In contrast, when the depression in ADW was managed with the tile riser, no significant differences were observed for time to peak and cumulative flow, while flow duration significantly increased. Average flow rate and peak flow rate at $\mathrm{ADW}$ when the tile riser was implemented was also significantly different, whereby the tile riser increased flow rates during the largest events and decreased flow rates during the smallest events (figure 5).

To further investigate why surface water management practices affected depression hydrology differently between fields, a water balance approach was utilized. Using measured discharge from both fields when they were managed with the blind inlet and measured infiltration rate, lateral subsurface contributions to discharge were computed (table 2). Substantially more lateral subsurface flow was calculated for ADW compared to $\mathrm{ADE}$ for flows $>25$ th percentile. Lateral subsurface flow accounted for $6.4 \%$ to $56.4 \%$ of total discharge from ADE when it was managed with the blind inlet, while lateral subsurface flow accounted for $6.0 \%$ to $76.6 \%$ of total discharge from ADW. The septic tile (90 cm depth) installed in the blind inlet was effectively functioning as additional subsurface tile line in both fields when the fields were managed with the blind inlet; however, the lower subsurface drainage intensity throughout the rest of the field (and resultant wetter antecedent conditions) in ADW resulted in larger subsurface flow contri-
Table 1

Analysis of covariance (ANCOVA) results. Since both fields were managed concurrently as blind inlets during several periods of the study (figure 2), the tile riser was considered as the treatment and the blind inlet as the control. Linear relationships between ADE and ADW sites were developed for periods of the study (1) when both depressions were managed with blind inlets, (2) when ADE was managed with the blind inlet and ADW was managed with the tile riser, and (3) when ADE was managed with the tile riser and ADW was managed with the blind inlet. Results shown graphically in figure 5 .

\begin{tabular}{|c|c|c|c|c|c|}
\hline \multirow{2}{*}{$\begin{array}{l}\text { Hydrograph } \\
\text { parameter }\end{array}$} & \multicolumn{2}{|c|}{ Site/treatment } & \multirow[b]{2}{*}{$R^{2}$} & \multirow[b]{2}{*}{ Slope† } & \multirow[b]{2}{*}{ Intercept $†$} \\
\hline & ADE & ADW & & & \\
\hline \multirow[t]{3}{*}{ Time to peak (d) } & Blind inlet & Blind inlet & 0.21 & 0.61 & 0.37 \\
\hline & Blind inlet & Tile riser & 0.42 & 0.53 & 0.30 \\
\hline & Tile riser & Blind inlet & 0.79 & $1.06 * *$ & 0.14 \\
\hline \multirow[t]{3}{*}{ Flow duration (d) } & Blind inlet & Blind inlet & 0.01 & 0.09 & 0.74 \\
\hline & Blind inlet & Tile riser & 0.30 & $0.45 *$ & 0.55 \\
\hline & Tile riser & Blind inlet & 0.71 & $0.87 * * *$ & 0.30 \\
\hline \multirow[t]{3}{*}{ Peak flow $\left(\mathrm{mm} \mathrm{h}^{-1}\right)$} & Blind inlet & Blind inlet & 0.08 & 0.63 & 0.24 \\
\hline & Blind inlet & Tile riser & 0.58 & $1.82 * * *$ & 0.12 \\
\hline & Tile riser & Blind inlet & 0.46 & 0.42 & $0.12 * * *$ \\
\hline \multirow[t]{3}{*}{ Average flow $\left(\mathrm{mm} \mathrm{h}^{-1}\right)$} & Blind inlet & Blind inlet & 0.07 & 0.93 & 0.11 \\
\hline & Blind inlet & Tile riser & 0.57 & $1.76^{*}$ & 0.05 \\
\hline & Tile riser & Blind inlet & 0.55 & 0.55 & $0.04 * * *$ \\
\hline \multirow[t]{3}{*}{ Cumulative flow (mm) } & Blind inlet & Blind inlet & 0.02 & 0.82 & 3.18 \\
\hline & Blind inlet & Tile riser & 0.84 & 1.90 & 1.47 \\
\hline & Tile riser & Blind inlet & 0.84 & 0.78 & $0.63 * *$ \\
\hline
\end{tabular}

* $p<0.05 ; * * p<0.01 ; * * * p<0.001$

†Statistical significance between treatment period (tile riser to blind inlet or blind inlet to tile riser) and control period (blind inlet to blind inlet) for both fields.

butions compared to the higher subsurface drainage intensity in ADE.

Differences in lateral subsurface flow contributions when the fields were managed with blind inlets help to not only explain the observed differential effects of surface water management practice on depression hydrology, but also observed differences in discharge frequency described previously. For instance, the tile riser decreased and increased flow duration at ADE and ADW, respectively, relative to the blind inlet (figure 5 ; table 1). The decreased flow duration with the tile riser as was found for ADE was expected due to slower infiltration rate into the blind inlet compared to the flow capacity of the tile riser. Given the greater subsurface drainage intensity (and smaller contributions of subsurface lateral flow when the blind inlet was operational) in ADE, differences in hydrologic characteristics between surface water management practices were largely driven by changes in surface processes. In contrast, the increased subsurface drainage intensity provided by the blind inlet at ADW may have resulted in drier antecedent conditions compared to when the field was managed with the tile riser, which resulted in a shorter flow duration when the blind inlet was operational. It is also feasible that increased frequency of discharge during the winter at ADW compared to ADE (i.e., figure 3) was due to lateral subsurface flows when it was managed with the blind inlet and increased surface ponding due to wetter antecedent conditions when it was managed with the tile riser. This suggests at ADW the observed differences in hydrologic characteristics between surface water management practices were determined by changes to both surface and subsurface processes. Results for the current study therefore suggest that existing subsurface tile drainage within a closed depression may significantly impact the hydrologic functioning of surface water management practices.

Management Implications. Results from the current study indicate that replacing a tile riser with a blind inlet does not increase the frequency of discharge from drained closed depressions. Blind inlets, however, may increase or decrease the duration of flow compared to a tile riser. Installing a blind inlet in a depression with lower sub- 


\section{Figure 5}

Relationships between ADE and ADW sites for event hydrograph characteristics when both fields were managed with blind inlets (black), when ADE was managed with a tile riser and ADW was managed with a blind inlet (red), and when ADW was managed with a tile riser and ADE was managed with a blind inlet (blue). Left panels show scatterplots of data, while right panels show linear regression lines. Regression lines denoted with an asterisk are significant at $p<$ 0.05; ANCOVA results are presented in table 1.
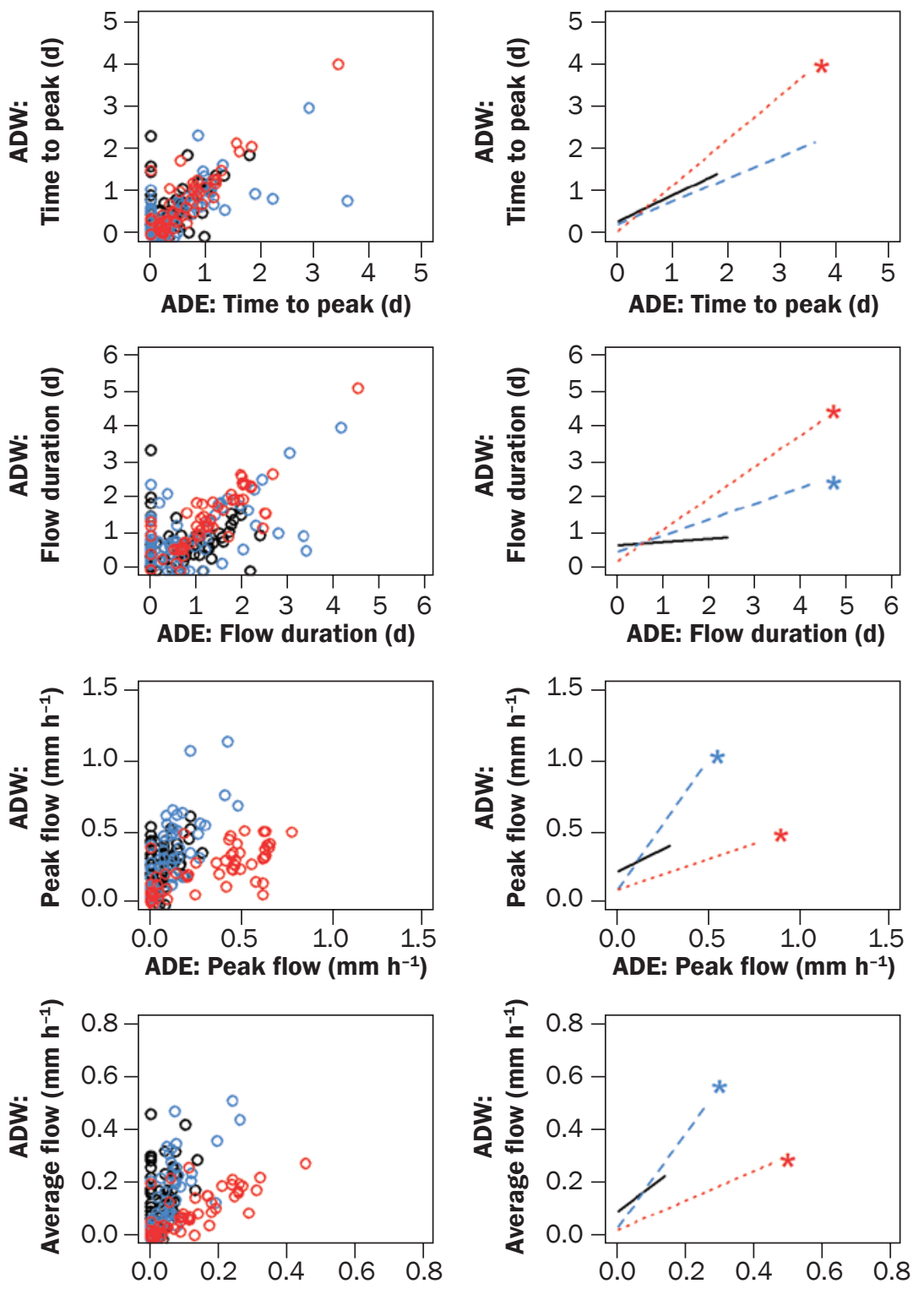

ADE: Average flow $\left(\mathrm{mm} \mathrm{h}^{-1}\right)$

ADE: Average flow $\left(\mathrm{mm} \mathrm{h}^{-1}\right)$
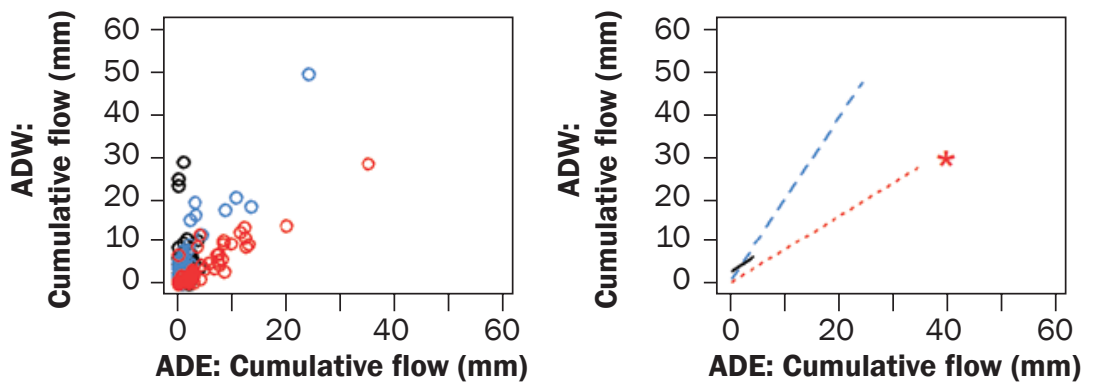

surface drainage intensity, similar to ADW, may result in shorter flow duration compared to the tile riser due to the additional subsurface drainage capacity provided by the septic tile lines in the blind inlet and potentially drier antecedent conditions compared to a tile riser. In contrast, installing a blind inlet in a depression with greater subsurface drainage intensity (i.e., ADE) may result in less cumulative flow compared to a tile riser, which could result in larger nutrient load reductions than a blind inlet installed in a depression with lower subsurface drainage intensity. Less cumulative flow at ADE when the depression was managed with the blind inlet is hypothesized to be the result of greater subsurface tile flow due to longer flow durations (i.e., longer periods of time for ponded water to infiltrate and become subsurface tile flow rather than surface flow) compared to when the depression was managed with the tile riser. Similar to many conservation practices, study results indicate that the effect of surface drainage water management practices on depression hydrology will largely be field-specific. It is important to note that nearly all of the research on blind inlets has been conducted at ADE and ADW (Smith and Livingston 2013; Smith et al. 2015; Feyereisen et al. 2015; Gonzalez et al. 2016); thus, more research on surface and subsurface hydrologic processes in drained closed depressions is needed at other locations to evaluate differences in surface drainage water management practices.

While the main objective of the current study was to evaluate changes in hydrology due to surface drainage water management practice, it is also important to discuss potential changes in water quality. Blind inlets were initially developed to filter eroded sediment in surface runoff (Smith and Livingston 2013). Declining infiltration rate likely due to accumulated sediment on the surface of the blind inlet provides evidence that blind inlets have the potential to substantially decrease sediment losses from closed depressions compared to a tile riser. If fields are frequently tilled like $\mathrm{ADE}$ and $\mathrm{ADW}$, then it may, however, be more cost-effective to switch to no-tillage practices (i.e., treating the cause of the problem) rather than to install a blind inlet (i.e., treating the symptom of the problem) as suggested by Oolman and Wilson (2003).

From 2006 through 2015, event flowweighted mean concentrations of soluble reactive phosphorus (SRP), total phospho- 


\section{Table 2}

Water balance for ADE and ADW sites when they were managed with a blind inlet. Measured cumulative flow during events combined with measured infiltration rates (2012; figure 4) was used to estimate subsurface lateral flow into the blind inlet. Flow values were estimated for each event and subsequently ranked by percentile. Values represent the average of each flow percentile classification.

\begin{tabular}{|c|c|c|c|c|}
\hline $\begin{array}{l}\text { Flow } \\
\text { percentile }\end{array}$ & $\begin{array}{l}\text { Cumulative flow } \\
\left(\mathrm{m}^{3} \text { event }^{-1}\right)\end{array}$ & $\begin{array}{l}\text { Vertical flow } \\
\text { into blind inlet* } \\
\left(\mathrm{m}^{3} \text { event }^{-1}\right)\end{array}$ & $\begin{array}{l}\text { Lateral flow into } \\
\text { blind inlet } † \\
\left(\mathrm{~m}^{3} \text { event }^{-1}\right)\end{array}$ & (\%) \\
\hline \multicolumn{5}{|l|}{ ADE } \\
\hline 0 to 25 & 7.55 & 7.07 & 0.48 & 6.4 \\
\hline 25 to 50 & 25.73 & 23.98 & 1.75 & 6.8 \\
\hline 50 to 75 & 55.37 & 47.35 & 8.02 & 14.5 \\
\hline 75 to 100 & 217.81 & 95.00 & 122.81 & 56.4 \\
\hline \multicolumn{5}{|l|}{ ADW } \\
\hline 0 to 25 & 10.73 & 10.09 & 0.64 & 6.0 \\
\hline 25 to 50 & 43.68 & 31.94 & 11.74 & 26.9 \\
\hline 50 to 75 & 145.53 & 63.19 & 82.34 & 56.6 \\
\hline 75 to 100 & 450.78 & 105.49 & 345.29 & 76.6 \\
\hline
\end{tabular}

rus (TP), and nitrate-nitrogen $\left(\mathrm{NO}_{3}-\mathrm{N}\right)$ were similar between the blind inlet and tile riser at both sites (figure 6). This could suggest that blind inlets do not filter out nutrients from surface runoff; however, since a large fraction of cumulative event flow, especially at ADW, is likely from lateral subsurface flow, it is not possible to discern the effectiveness of the blind inlet on filtering nutrients in surface runoff. Significant reductions in nutrient and pesticide load have been reported for ADE and ADW when the depressions were drained with the blind inlet compared to the tile riser (Smith and Livingston 2013; Smith et al. 2015; Feyereisen et al. 2015; Gonzalez et al. 2016). For example, Smith and Livingston (2013) and Smith et al. (2015) suggested that the blind inlet decreased SRP loads during the growing season (April 1 to November 15) between $65 \%$ and $83 \%$ compared to the tile riser. These previous studies directly compared ADE and ADW while one was managed with the blind inlet and the other with the tile riser, with ADE in blind inlet mode and ADW in tile riser mode for the majority of monitored events (e.g., ADE was in blind inlet mode for 9 of 11 events in Smith and Livingston [2013]). Results from the current study agree with previous findings: the blind inlet significantly decreased cumulative flow at ADE, and, as a result, likely nutrient loads relative to the tile riser. In contrast, if ADW would have been the field site in blind inlet mode during the previous studies, then blind inlet effectiveness would have been substantially less, as results from the current study showed that the blind inlet at ADW did not significantly decrease cumulative flow (and likely nutrient loads). Consequently, the range of reported nutrient load reductions for blind inlets compared to tile risers should likely be much broader (perhaps $0 \%$ to $80 \%$ ) rather than nutrient load reductions reported previously (Smith and Livingston 2013; Smith et al. 2015). The small number of events with water quality data unfortunately precludes rigorous statistical testing using a BACI study design. Thus, results from the current study indicate that previously reported blind inlet load reductions at ADE and ADW should be interpreted with caution, and that differences in blind inlet effectiveness between fields were likely due to differing hydrologic processes.

\section{Summary and Conclusions}

Surface water management practices in agricultural closed depressions significantly influence hydrograph characteristics including flow duration and cumulative flow. Results show that the effect of surface water management practice on hydrograph characteristics may, however, be site-specific and dependent on hydrologic processes.
Replacing a tile riser with a blind inlet resulted in different behavior between ADE and ADW. Using a water balance approach, findings suggest that differences between sites may be due to the extent of subsurface tile drainage within the closed depression. Installing a blind inlet in a depression with lower subsurface drainage intensity, similar to ADW, may result in shorter flow duration compared to the tile riser due to the additional subsurface drainage capacity provided by the septic tile lines in the blind inlet and potentially drier antecedent conditions compared to a tile riser. In contrast, installing a blind inlet in a depression with greater subsurface drainage intensity (i.e., ADE) may result in less cumulative flow compared to a tile riser due to a larger fraction of ponded surface water infiltrating and becoming subsurface tile flow rather than surface flow, which could result in larger nutrient load reductions than a blind inlet installed in a depression with lower subsurface drainage intensity. These results highlight the strong connection between surface and subsurface hydrologic processes in closed depressions and the potential implications for both water quantity and water quality. Few studies have examined the hydrology of closed depression despite the large number located throughout the midwestern United States. Thus, future research quantifying the relationship between surface runoff, subsurface tile drainage, and antecedent soil moisture in drained closed depressions is needed.

Blind inlet infiltration rate declined over the study period due to the accumulation of eroded sediment on top of the surface of the blind inlet. Where placed in fields that are managed with (repeated) tillage, landowners should expect to replace blind inlets at least once every 10 years to maintain depression surface drainage. Data on the longevity of blind inlets under no-tillage practices are needed to benchmark this finding. While the blind inlet was successful in filtering sediment in runoff water, it was not possible to discern the effectiveness of the blind inlet on filtering nutrients given the large fraction of cumulative event flow, especially at ADW, that was likely from lateral subsurface flow and the small number of monitored events with water quality data. Event flow-weighted mean concentrations were similar between the tile riser and blind inlet; thus, reductions in nutrient load likely will depend on how the hydrology of the 


\section{Figure 6}

Event flow-weighted mean nitrate-nitrogen $\left(\mathrm{NO}_{3}-\mathrm{N}\right)$, soluble reactive phosphorus (SRP), and total phosphorus (TP) concentration when the depressions at ADE and ADW sites were managed with the tile riser and blind inlet. Events with water quality data were collected during the growing season only (April 1 to November 15) between 2006 and 2015. Note: $y$-axes are shown on a log-scale.

\section{(a)}

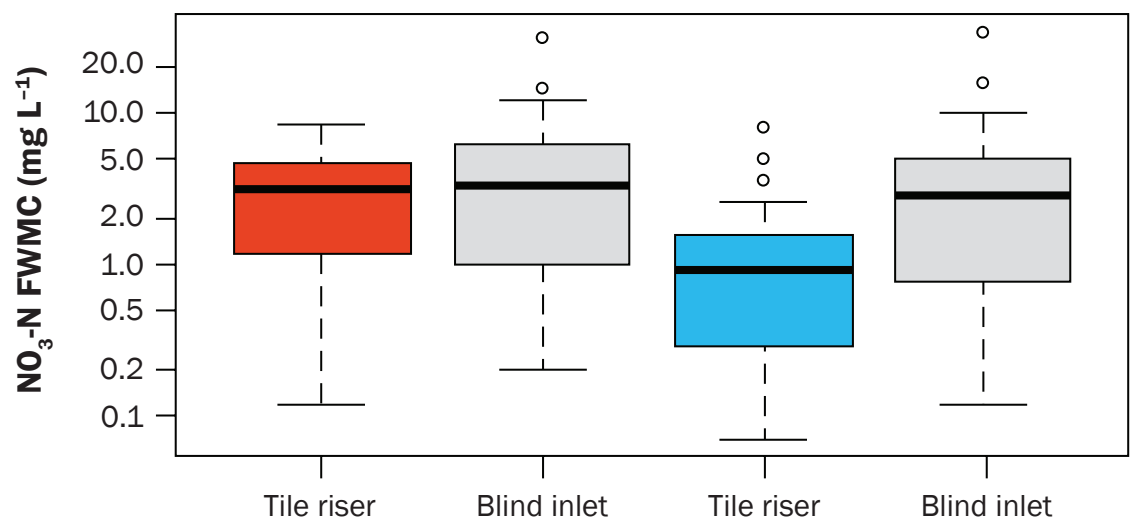

(b)

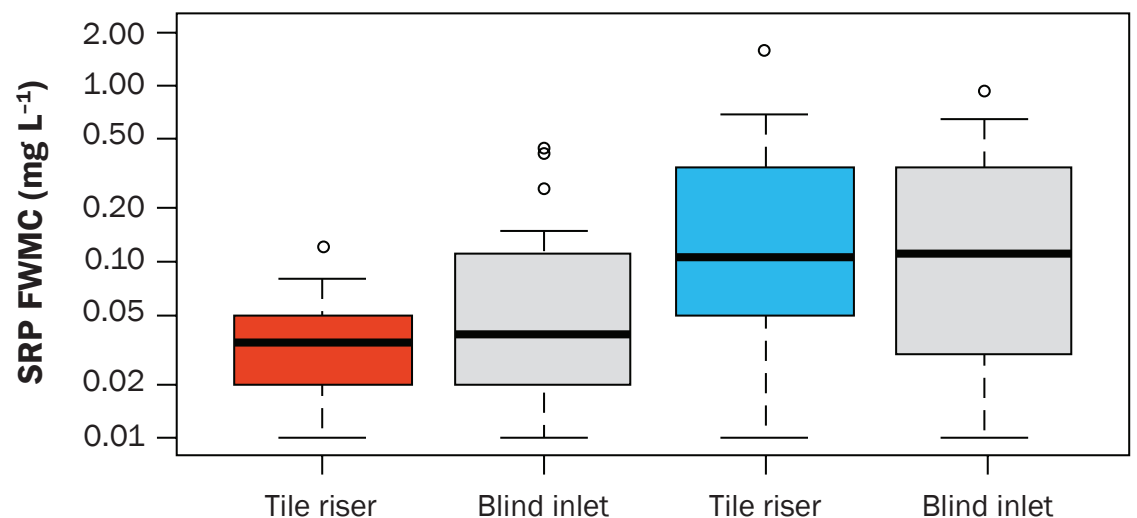

(c)

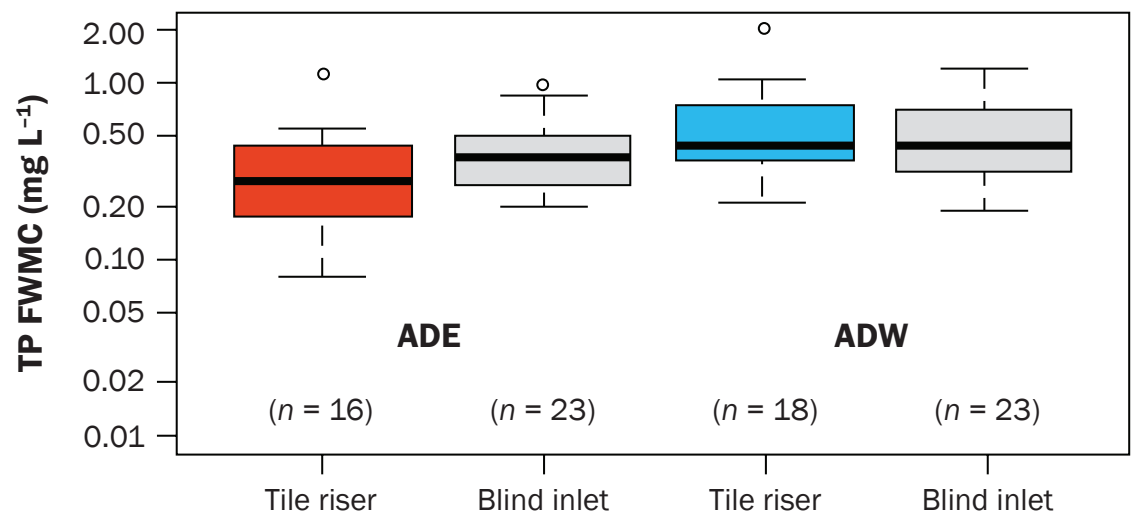

depression is altered due to the installation of the blind inlet.

\section{Acknowledgements}

The authors would like to thank the landowners of the field who have graciously allowed us to conduct research on their farm for over 10 years. We would also like to acknowledge the staff at the National Soil Erosion Research Lab and the
DeKalb County (Indiana) Soil and Water Conservation District for their assistance with site maintenance, data collection, and sample analysis. This research and assessment was supported by the USDA Natural Resources Conservation Service Conservation Effects Assessment Project Watershed Assessment Studies and Agricultural Research Service National Program 211.

\section{Disclaimer}

USDA is an equal opportunity provider and employer. Mention of trade names or commercial products in this publication is solely for the purpose of providing specific information and does not imply recommendation or endorsement by the USDA

\section{References}

Amado, A.A., M. Politano, K. Schilling, and L. Weber. 2016. Investigating hydrologic connectivity of a drained prairie pothole region wetland complex using a fully integrated, physically-based model. Wetlands 38:233245(2018), DOI:10.1007/s13157-016-0800-5.

Bishop, R.A., A.J. Joens, and J. Zohrer. 1998. Iowa's wetlands, present and future with a focus on prairie potholes. Journal of the Iowa Academy of Science 88:11-16.

Blann, K.L., J.L. Anderson, G.R. Sands, and B. Vondracek. 2009. Effects of agricultural drainage on aquatic ecosystems: A review. Critical reviews in Environmental Science and Technology 39:909-1001.

Clausen, J.C., and J. Spooner. 1993. Paired watershed study design. Rep. 841-F-93-009. Washington, DC: US Environmental Protection Agency, Office of Water.

Dreimanis, A. 1977. Late Wisconsin glacial retreat in the Great Lakes region, North America. Annals of the New York Academy of Sciences 288:70-89.

Feyereisen, G.W., W. Francesconi, D.R. Smith, S.K. Papiernik, E.S. Krueger, and C.D. Wente. 2015. Effect of replacing surface inlets with blind or gravel inlets on sediment and phosphorus subsurface drainage losses. Journal of Environmental Quality 44:594-604.

Gonzalez, J.M., D.R. Smith, S. Livingston, E. WarnemuendePappas, and M. Zwonitzer. 2016. Blind inlets: Conservation practices to reduce herbicide losses from closed depressional areas. Journal of Soils and Sediments 16:1921-1932.

Huang, S., C. Young, O.I. Abdul-Aziz, D. Dahal, and M. Feng. 2013. Simulating the water budget of a prairie pothole complex from LiDAR and hydrological models in North Dakota, USA. Hydrological Sciences Journal 58:1434-1444.

King, K.W., N.R. Fausey, and M.R. Williams. 2014. Effect of subsurface drainage on streamflow in an agricultural headwater watershed. Journal of Hydrology 519:438-445.

King, K.W., M.R. Williams, W.A. Dick, and G.A. LaBarge. 2016. Decreasing phosphorus loss in tile-drained landscapes using flue gas desulfurization gypsum. Journal of Environmental Quality 45:1722-1730. 
Laflen, J.M., J.L. Baker, R.O. Hartwig, W.F. Buchele, and H.P. Johnson. 1978. Soil and water loss from conservation tillage systems. Transactions of the ASAE 21:881-885.

Lam, W.V., M.L. Macrae, M.C. English, I.P. O'Halloran, J.M. Planch, and Y. Wang. 2016. Seasonal and eventbased drivers of runoff and phosphorus export through agricultural tile drains under sandy loam soil in a cool temperate region. Hydrological Processes 30:2644-2656.

Li, S., R. Bhattarai, R.A. Cooke, T. Rendall,V. Dahal, and P.K Kalita. 2017. Assessment of surface inlets performance on sediment transport to subsurface drainage system. Applied Engineering in Agriculture 33:217-224.

Mausbach, M.J., and A.R. Dedrick. 2004. The length we go: Measuring environmental benefits of conservation practices. Journal of Soil and Water Conservation 59(5):96A-103A.

Miller, T.P., J.R. Peterson, C.F. Lenhart, and Y. Nomura. 2012. The agricultural BMP handbook for Minnesota. Minnesota Department of Agriculture. https://wrl. mnpals.net/islandora/object/WRLrepository\%3A2749.

Mueller, M., and G.Wehrenberg. 1994. SWCD methodology of land use assessment. St. Paul, MN: Minnesota Pollution Control Agency.

Norton, L.D. 1986. Erosion-sedimentation in a closed drainage basin in northwest Indiana. Soil Science Society of America Journal 50:209-213.

Oolman, E.B., and B.N. Wilson 2003. Sediment control practices for surface tile inlets. Applied Engineering in Agriculture 19:161-169.

R Development Core Team. 2011. R: A language and environment for statistical computing. Vienna, Austria: R Foundation for Statistical Computing.

Schilling, K.E., C.F. Wolter, T.M. Isenhart, and R.C. Schultz. 2015. Tile drainage density reduces groundwater travel times and compromises riparian buffer effectiveness. Journal of Environmental Quality 44:1754-1763.

Shaw, D.A., A. Pietroniro, and L. Martz. 2013. Topographic analysis for the prairie pothole region of Western Canada. Hydrological Processes 27:3105-3114.

Shaw, D.A., G.Vanderkamp, F.M. Conley, A. Pietroniro, and L. Martz. 2012. The fill-spill hydrology of prairie wetland complexes during drought and deluge. Hydrological Processes 26:3147-3156.

Shipitalo, M.J., and M.D.Tomer. 2015. Quantifying the effects of alternative surface inlet protection strategies on water quality. Leopold Center Completed Grant Reports. 478. https://lib.dr.iastate.edu/leopold_grantreports/478.

Skaggs, R.W., M.A. Breve, and J.W. Gilliam. 1994 Hydrologic and water quality impacts of agricultural drainage. Critical Reviews in Environmental Science and Technology 24:1-32.

Smith, D.R., W. Francesconi, S.J. Livingston, and C. Huang. 2015. Phosphorus losses from monitored fields with conservation practices in the Lake Erie Basin, USA. Ambio 44:S319-S331.

Smith, D.R., and S.J. Livingston. 2013. Managing farmed closed depressional areas using blind inlets to minimize phosphorus and nitrogen losses. Soil Use and Management 29:94-102.

Smith, D.R., S.J. Livingston, B.W. Zuercher, M. Larose, G.C. Heathman, and C. Huang. 2008. Nutrient losses from row crop agriculture in Indiana. Journal of Soil and Water Conservation 63(6):396-409, doi:10.2489/ jswc.63.6.396.

Tomer, M.D., C.G.Wilson, T.B. Moorman, K.J. Cole, D. Heer, and T.M. Isenhart. 2010. Source-pathway separation of multiple contaminants during a rainfall-runoff event in an artificially drained agricultural watershed. Journal of Environmental Quality 39:882-895.

USDA NRCS (Natural Resources Conservation Service). 2010. Conservation practice standard: Underground outlet. Washington, DC: USDA Natural Resources Conservation Service. https://www.nrcs.usda.gov/ Internet/FSE_DOCUMENTS/nrcs143_025875.pdf.

van derValk, A.G., and R.L. Pederson. 2003. The SWANCC decision and its implications for prairie potholes. Wetlands 23:590-596.

Williams, M.R., K.W. King, and N.R. Fausey. 2015. Drainage water management effects on tile discharge and water quality. Agricultural Water Management 148:43-51.

Wilson, B.N., H.V. Nguyen, U.B. Singh, S. Morgan, P. Van Buren, D. Mickelson, E. Jahnke, and B. Hansen. 1999. Evaluations of alternative designs for surface inlets using prototype studies. Report 417121. St. Paul, MN: Minnesota Department of Agriculture. 